\title{
Dipeptidyl peptidase-4 inhibitors improve arterial stiffness, blood pressure, lipid profile and inflammation parameters in patients with type 2 diabetes mellitus
}

Lea Duvnjak ${ }^{1,2}$ and Kristina Blaslov ${ }^{1 *}$

\begin{abstract}
Background: This uncontrolled open label study evaluated the effect of dipeptidyl peptidase-4 inhibitors (DPP-4i): sitagliptin and vildagliptin on augmentation index standardized for 75 beats per minute (cAiX@75), blood pressure (BP), lipid profile and high-sensitivity C-reactive protein (hsCRP) in patients with type 2 diabetes mellitus (T2DM).

Methods: Fifty-one well-regulated T2DM patients were randomly assigned to either sitagliptin or vildagliptin (100 mg/day) for 3 months continuing their previous treatment. Lipid profile, cAiX@75, hsCRP, glycated hemoglobin (HbA1c) were measured at baseline at 4,8 and 12th week were accessed. cAiX@75 and pulse wave velocity (PWV) were determined by SphygmoCor device.

Results: Following DPP-4 treatment there was a significant reduction in total serum cholesterol (5.18 vs $4.62 \mathrm{mmol} / \mathrm{L}$ ), low-density lipoprotein (2.89 vs $2.54 \mathrm{mmol} / \mathrm{L}$ ), hsCRP (3.21 vs $1.95 \mathrm{mg} / \mathrm{L}$ ), cAiX@75 (24.5 vs 22.3) and central systolic BP (131.8 vs $119.5 \mathrm{mmHg}$ ). The sitagliptin treated group reached cAiX@75 reduction earlier in the study period while neither sitagliptin or vildagliptin use resulted in the significant $\mathrm{HbA} 1 \mathrm{c}$ reduction.
\end{abstract}

Conclusion: The treatment with DPP-4i: sitagliptin and vildagliptin provides favorable metabolic and vascular effects beyond glucose-control. Further studies are required to elucidate their implication in metabolic pathways.

Keywords: Dipeptidyl peptidase-4, Type 2 diabetes mellitus, Blood pressure, Augumentation index

\section{Background}

According to the Framingham study type 2 diabetes mellitus (T2DM) is associated with a twofold to fourfold increased risk for cardiovascular disease (CVD) [1]. This is due to diabetes related metabolic disorders: chronic hyperglycemia and dyslipidemia along with oxidative stress and low grade inflammation [2]. Although antihyperglycemic drugs improve glycemic control, the cardiovascular benefits to certain subgroups of T2DM patients has been established only for metformin and pioglitazone $[3,4]$. There is a lack of evidence that the therapeutic

\footnotetext{
*Correspondence: kblaslov@gmail.com

${ }^{1}$ Vuk Vrhovac Clinic for Diabetes, Endocrinology and Metabolic diseases,

Merkur University hospital, Dugi dol 4a, Zagreb, Croatia

Full list of author information is available at the end of the article
}

strategies targeting pancreatic $\beta$ cell dysfunction and insulin resistance (IR) reduce the cardiovascular risk in patients with diabetes [5]. This notion raises the need for alternative therapies that provide substantial benefits without side effects. Among emerging anti-diabetic candidates, incretin-based therapies carry a special cardiovascular implication.

Incretins are a group of gastrointestinal hormones, among which the glucagon-like peptide 1 (GLP-1) and the glucose dependent insulinotropic peptide (GIP) are released in response to nutrient ingestion, stimulating insulin and suppressing glucagon secretion [6]. GLP-1 also seems to have some beneficial effect on pancreatic $\beta$-cells preservation in experimental models [7]. However, this actions are limited due to its rapid inactivation by the dipeptidyl peptidase-4 (DPP-4) enzyme $[8$, 
9]. DPP-4 inhibitors spare the GLP-1 breakdown and improve glycemic control by consequential increase insulin secretion $[9,10]$.

Beyond its beneficial action on metabolic control, GLP-1 seems to exert favorable cardiovascular effect mediated partially through a specific GLP-1 receptor on cardiomyocytes, vascular endothelium and vascular smooth muscle cells [10]. The administration of inherent GLP-1 causes acute animal aortic dilation [11]. This observed vasodilatory properties are probably mediated through GLP-1 metabolites and independently of the GLP-1 receptor, acting instead through an NO/cGMPdependent mechanism [12].

DPP-4 has several non-incretin substrates involved in inflammation, immunity and cardiovascular system [13] and its expression on endothelial surface suggests that its inhibition might reduce the vascular tone [14]. Some clinical data suggest the beneficial effects of DPP-4 inhibitors on hypertension, dyslipidemia and CRP have been cited in the literature [15-18]. This suggests that those might have a potential to reduce the CVD burden among patients with T2DM.

Arterial stiffness (AS) is a strong independent predictor of CVD in several populations, including T2DM patients [19] being increasingly recognized as a surrogate end point for CVD [20]. The effect of DPP-4 inhibition on AS is still a matter of debate [15-17] and the direct comparison of different DPP-4 inhibitors impact on CVD risk factors is yet to be established.

Thus, we aimed to evaluate the effect of DPP-4 inhibitors on CVD risk factors: central obesity, lipidemia, hsCRP, glycaemia and blood pressure with a special emphasis on AS and related parameters, i.e. central pulse pressure (PP), central blood pressure (cBP) and pulse wave velocity (PWV) in metabolically well regulated T2DM patients. Second we compared the effect of two different DPP-4 inhibitors: sitagliptin and vildagliptin on the observed parameters.

\section{Methods}

This was an uncontrolled open-label, parallel-arm, randomized 12 week study conducted in the In-patient Clinic for Diabetes, endocrinology and metabolic diseases Vuk Vrhovac, Zagreb, Croatia.

Type 2 diabetic patients of either gender, aged between 40 and 75 years were eligible for the inclusion in the study. Selected non-inclusion criteria were insulin or (current or previous 3 months) treatment with any incretin-based treatment strategy including GLP-1 analogues and DPP-4 inhibitors. Furthermore, patients with macrovascular complications such as significant arterial obliteration detected by imaging methods, an acute cardiovascular event (e.g. myocardial infarction), unstable angina or stroke within six months prior to enrollment, impaired glomerular filtration rate $\left(<60 \mathrm{ml} / \mathrm{min} / 1.73 \mathrm{~m}^{2}\right)$ and urine albumin excretion rate $>300 \mathrm{mg} / 24 \mathrm{~h}$.

After the screening period patients were randomized to receive either sitagliptin (50 mg twice daily) or vildagliptin (50 mg twice daily) in addition to continuing their antidiabetic background treatment. Also, the antihypertensive and lipid-lowering drugs were unchanged during the study period. Randomization procedures were performed by principal investigator or his/her delegate by physical method of randomization using shuffle sealed envelopes with treatment allocations inside. Patients both groups were instructed to strictly maintain dietary habits and daily activities during the course of the study. They were assessed at the outpatient visit four times: at baseline, 4, 8 and 12th week. Blood samples for biochemical measurements were collected at each visit as well as physical examination including anthropometric parameters while the carotid-femoral (cf) PWV and 24-h blood pressure record was measured at baseline and at the end.

The study protocol was approved by the Ethic Committee of the Merkur University Hospital, Zagreb, Croatia and the study was performed according to Declaration of Helsinki and "good clinical practice" (GCP) guidelines. Written informed consent was obtained from all the study participants before the study entry.

The central aortic pressure waveform can be used to determine central systolic and diastolic BP, (dBP) central PP and augmentation pressure (AP). Central PP and augmentation index (cAIx; AP as a proportion of PP) are markers of AS showing good correlation with cardiovascular morbidity an mortality $[21,22]$. The central arterial waveform was derived by using the SphygmoCor ${ }^{\mathrm{TM}}$ System (AtCor Medical, Sydney, Australia). The radial artery waveform was recore from the radial artery at the wrist, using high-fidelity applanation tonometry (Millar Instruments, Houston, Texas). The SphygmoCor ${ }^{\mathrm{TM}}$ System automatically generates the corresponding central (aortic) waveforms from an averaged radial artery waveform. From the central systolic and diastolic BP as well as AP and cAIx were derived. The cAIx was normalized to hearth rate of 75 beats per minute (cAIx@75).

PWV is a direct measure of AS of large arteries. For the determination of aortic PWV, waveforms of the common carotid artery and femoral artery were obtained using SphygmoCor ${ }^{\mathrm{TM}}$. PWV was calculated as the distance between suprasternal notch and the femoral artery recording site, and divided by the time interval between the feet of the flow waves.

Three readings were obtained from the right arm of seated participants while their arm was supported at heart level; 1 trained observer took all measures using an automatic office BP device (OMRON Intellisense 
HEM-907) according to JNC VIII criteria [23]. For 24-h ambulatory blood pressure (ABP) measurements, participants were fitted with a SpaceLabs 90207 ABP monitors. The cuff was secured around the participant's non-dominant arm, and it remained there during the entire test. Measurements were automatically repeated if an error occurred. The adult cuff and the large adult cuff were used for arm circumferences of $24-31$ and $32-42 \mathrm{~cm}$, respectively.

Body weight (BW) was measured with light clothing on a balance scale and height to the nearest $0.5 \mathrm{~cm}$ using a meter that was stabilized on the wall. BMI was calculated as weight (kilograms) divided by height (meters) squared. Waist circumference was measured at minimal respiration by a flexible tape parallel to the floor and immediately above the iliac crest.

All laboratory tests were performed after a $12 \mathrm{~h}$ overnight fast. Biochemistry, including glucose, lipid levels (TC; high density lipoprotein cholesterol, HDL-C; and TG) liver enzymes (alanine transaminase, ALT; aspartate transaminase, AST, hsCRP and creatinine, were evaluated on an Olympus analyzer (Olympus AU600, Olympus Optical Co., Tokyo, Japan). Low-density lipoprotein cholesterol (LDL-C) was calculated using Friedewald's formula [24].

To perform a formal sample size calculation the primary endpoint was set to be the effect of sitagliptin and vildagliptin on central SBP [15]. We estimated that a total of 51 patients will be needed for this two-treatment parallel-design study with the probability (power) of 99 percent that the study will detect a treatment difference at a two-sided 0.05 significance level. All the data are entered in triplicate in Open Document Spreadsheet database and the analysis was performed using SPSS 17.0 (Chicago, IL, USA).

Normality of distribution was confirmed by Shapiro-Wilk test prior to further analysis. Normally distributed data were compared by paired $t$ test and two-way ANOVA and expressed as mean \pm standard deviation. A two sided $P$ value $<0.05$ was considered significant.

\section{Results}

Fifty-one patient were enrolled in the study and all of them completed all four visits. There were 30 (58.8\%) males. Vildagliptin $2 \times 50 \mathrm{mg} /$ day was added to current diabetes therapy reigment in $20(39.21 \%)$ patients at the point treated with metformin only (up to $3 \mathrm{~g} ; \mathrm{N}=17$ ) and 3 patients with gliclazide $60 \mathrm{mg} /$ day + metformin $2 \mathrm{~g} /$ day. Sitagliptin $2 \times 50 \mathrm{mg} /$ day was added to 31 $(60.79 \%)$ patient treated with metformin (up to $3 \mathrm{~g} /$ day; $\mathrm{N}=30)$ and one patient treated with metformin (2.5 g and gliclazide $60 \mathrm{mg} /$ day).
After 12-weeks of treatment with DPP-4 inhibitors, BMI remained almost unchanged $\left[\left(28.8(3.5) \mathrm{kg} / \mathrm{m}^{2}\right.\right.$ vs $\left.28.6(3.5) \mathrm{kg} / \mathrm{m}^{2}\right), \mathrm{p}=\mathrm{NS}$ ] while the waist circumference significantly decreased mean $\mathrm{HbA1c}$ value remained unchanged (Table 1). The group experienced a mean -4.41 (2.03) $\mathrm{mmHg}$ of 24-hour SBP reduction and -4.65 (2.36) $\mathrm{mmHg}$ 24-hourDBP reduction. Total and well as LDL cholesterol significantly dropped as well as hsCRP concentration. The treatment also resulted in triglycerides concentration reduction (Table 1).

A significant reduction in cAIX@75, central SBP, DBP as well as office SBP and DBP was observed (Table 2). The PWV change of $-0.40(0.90) \mathrm{m} / \mathrm{s}$ was also notified, however, it did not reach the statistical significance [8.59 (0.33) vs $8.42(0.28), \mathrm{p}=0.816]$.

To evaluate the pharmacological action of DPP-4 inhibitors more precisely, we analyzed the results of DPP-4 treated cohort by stratifying them to sitagliptin and vildagliptin treated group. Sitagliptin resulted in significant oSBP [136.2 (12.3) vs 131.7 (10.5) $\mathrm{mmHg}$, $\mathrm{p}=0.037]$ and oDBP [84.8 (6.8) vs 74.1 (9.8) $\mathrm{mmHg}$, $\mathrm{p}=0.001]$ reduction while vildagliptin reached the significance only regarding oDBP [82.3 (10.1) vs 77.2 (10.4) $\mathrm{mmHg}, \mathrm{p}=0.007]$. cDBP was also significantly reduced only for sitagliptin group (78.8 (9.6) vs 73.8 (9.6) $\mathrm{mmHg}, \mathrm{p}=0.002$ ). In addition, hsCRP reduction was significant only for the sitagliptin group and was superior to vildagliptin $[-0.84(0.31) \mathrm{vs}-0.31(0.03) \mathrm{mg} / \mathrm{L}$, $\mathrm{p}=0.017]$. Sitagliptin was superior to vildagliptin in cAiX@75 reduction in the 8th week of the study (25.3 vs $26.4, \mathrm{p}=0.006$ ), however, the difference was lost by the study end (Fig. 1a). Finally, at the 12th week sitagliptin treated group had significantly lower cSBP compared to vildagliptin group (117.8 vs 122.4, $\mathrm{p}=0.046$ ) (Fig. 1b)

Table 1 Clinical characteristics at the begining and at the study end $(\mathbf{N}=\mathbf{5 1})$

\begin{tabular}{lccr}
\hline & Baseline & 12-weeks after & P \\
\hline Waist circumference (cm) & $103.3(12.3)$ & $101.4(11.8)$ & 0.012 \\
24 h SBP (mmHg) & $125.74(13.41)$ & $123.54(10.87)$ & $<0.001$ \\
24 h DBP (mmHg) & $74.49(7.59)$ & $73.67(7.45)$ & 0.281 \\
HbA1c (\%) & $6.9(1.1)$ & $6.9(0.7)$ & 0.461 \\
Cholesterol (mmol/L) & $5.18(1.0)$ & $4.62(1.60)$ & 0.001 \\
HDL-C (mmol/L) & $1.29(0.24)$ & $1.31(0.23)$ & 0.973 \\
LDL-C (mmol/L) & $2.89(0.84)$ & $2.54(0.85)$ & 0.005 \\
Triglycerides (mmol/L) & $2.26(1.35)$ & $1.81(0.91)$ & 0.001 \\
hsCRP (mg/L) & $3.21(0.86)$ & $1.95(1.59)$ & 0.009 \\
\hline
\end{tabular}

Data are expressed as mean (SD), HbA1c gycated haemoglobin, Chol cholesterol, $H D L-C$ high density cholesterol, $L D L-C$ low density cholesterol, Tgc triglycerides, hsCRP high sensitive $C$-reactive protein 
Table 2 Hemodynamic responses to DPP-4 inhibitors in patients with type 2 diabetes during treatment

\begin{tabular}{lccccc}
\hline $\mathbf{N}=\mathbf{5 1}$ & Week 0 & Week 4 & Week 8 & Week 12 & P \\
\hline AiX@75 & $24.5(9.3)$ & $23.4(10.5)$ & $23.2(7.9)$ & $22.3(6.8)$ & 0.031 \\
CSBP $(\mathrm{mmHg})$ & $131.8(12.9)$ & $128.6(11.7)$ & $124.6(10.5)^{\mathrm{a}}$ & $119.5(15.4)^{\mathrm{a}}$ & 0.001 \\
$\mathrm{CDBP}(\mathrm{mmHg})$ & $79.8(6.8)$ & $79.0(8.2)$ & $77.5(11.0)$ & $77.2(14.1)$ & 0.003 \\
OSBP (mmHg) & $141.8(10.2)$ & $139.1(13.1)$ & $135.1(12.1)^{\mathrm{a}}$ & $131.8(18.3)^{\mathrm{a}}$ & 0.042 \\
ODBP (mmHg) & $82.7(1.9)$ & $78.8(12.4)$ & $78.2(7.6)$ & $75.6(10.5)$ & 0.001 \\
\hline
\end{tabular}

Data are expressed by mean (SD), AIX@75 augumentation index standardized for 75 beats per minute, $C S B P$ central systolic blood pressure, $C D B P$ central diastolic blood pressure, $O S B P$ office systolic blood pressure, $O D B P$ office diastolic blood pressure

a The large decrease in the CSBP and oSBP as well as STD which is large might be due to three patients who experienced a high cSBP reduction as follows: 126-112, 133-116 and 146-124 mmHg while for the same patients the oSBP were: $132-111,144-133$ and $154-123 \mathrm{mmH}$

although the reduction was not significant when compared to the CSBP value at the study beginning for neither gliptin.

\section{Discussion}

The major finding of our study is that the 12-week treatment with DPP-4 inhibitors reduces the AS, PWV and 24-h SBP in T2DM patients. Furthermore, we showed that sitagliptin results in AS reduction earlier in the treatment period when compared to vildagliptin which might be due to their pharmacokinetic and pharmacodynamics properties [25]. However, the use of DPP-4 i did not result in mean HbA1c change during the study period.

There is accumulating evidence on global increase in the rates of T2DM associated cardiovascular events [26]. Obesity related inflammatory mediators, such as hsCRP are increased in diabetic state so inflammation related oxidative stress along with dyslipidemia seems to play a key role in the pathogenesis of vascular dysfunction [27-30]. In addition, increased AS, reduced aortic dispensability was shown in diabetic compared to nondiabetic population [31, 32]. Several studies reported AS as a strong predictor of cardiovascular morbidity and all-cause mortality in different populations and moreover, an independent predictor of 10 -year mortality in patients with diabetes [21,22].

Besides glycemic control, incretin-based treatment strategies for diabetes have focused on the reduction of CVD and its complications. There is a growing body of evidence suggesting that GLP-1-mimetics therapies have antiatherosclerotic and anti remodeling properties $[11,12]$. However, if GLP-1 increase by DPP-4 inhibition exhibits the same vascular profile remains to be established.

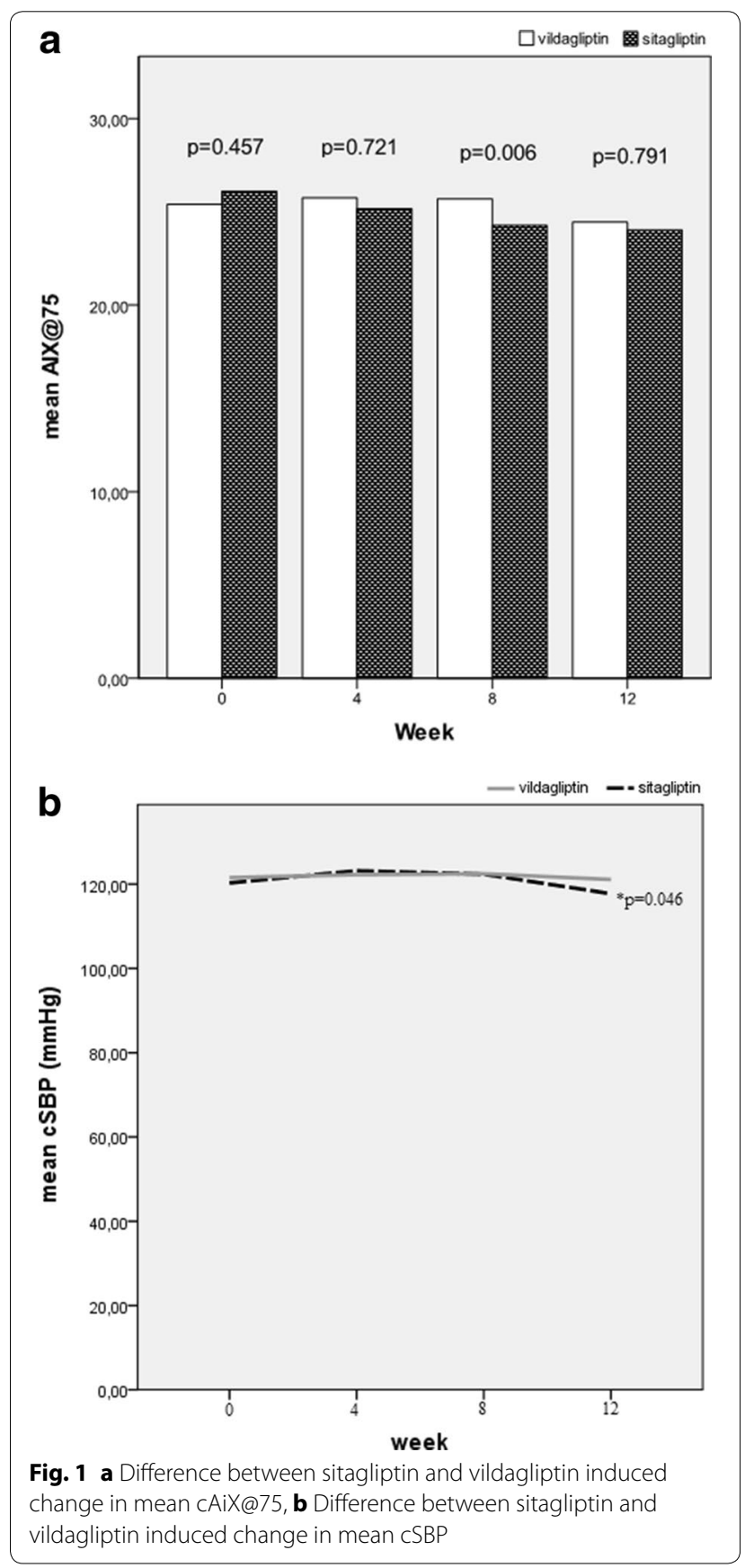

It was recently shown that 6 weeks treatment with saxagliptin tends to improve central hemodynamics in T2DM patients [33]. Vildagliptin was reported to to improve AS in poorly regulated T2DM patients [34, 35] which is partially in accordance with our results. In a study by Mistry et al. [36] sitagliptin produced small but statistically significant reductions of $2-3 \mathrm{mmHg}$ systolic and 1.6$1.8 \mathrm{mmHg}$ diastolic BP measurements acutely (day 1 ) and 
at steady state (day 5) in nondiabetic patients with mild to moderate hypertension. Similar was reported recently by Marney et al. [37] in patients suffering from metabolic syndrome patients during placebo and low-dose ACE inhibition (5 mgenalapril), sitagliptin lowered blood pressure. These results are highly supported by experimental animals studies: AS, as assessed by PWV, was significantly increased in Western Diet fed mice (16 \% increase) and was markedly decreased by DPP-4 inhibition [38].

We showed that both sitagliptin and vildagliptin treatment results in a significant hsCRP concentration reduction which is in accordance with the study data of Satoh-Asahara et al. [39] who were the first to report that sitagliptin treatment results in hsCRP reduction which was later confirmed for vildagliptin as well by Zografou et al. [35].

The addition of DPP-4 inhibitors to metformin (and gliclazide) also resulted in moderate waist circumference reduction. This is in agreement with previous studies and explained by the fact that although unlike mimetics, which boost GLP-1 activity leading to body weight reduction, DPP-4 inhibition works by slowing incretins degradation, therefore the level of circulating GLP-1 in inhibition therapy is significantly increased [40]. Furthermore, Koren et al. [17] recently reported a significant triglyceride concentration decrease in T2DM patients by $0.2 \pm 0.5 \mathrm{mmol} / \mathrm{L}$ following sitagliptin treatment, while the change in the total serum cholesterol, LDL- and HDL-cholesterol did not reach the statistical significance. We also demonstrated a significant drop in triglyceride concentration, but in addition, we showed a significant LDL- and total serum cholesterol reduction which is in accordance with the data from the most recent meta-analysis discussing the DPP-4i on lipid profile [41]. Improvement of this common pattern of dyslipidemia in T2DM indicates that it might be a treatable risk factor for subsequent CVD.

Many pathophysiological mechanisms might explain these results. First, DPP-4 inhibition certainly acts partially throw increasing incretin levels (GLP-1) and the recent meta-analysis definitely indicate their cardiac friendly lipid profile [42]. Previous animal studies have shown that GLP-1 can induce a NO-dependent or -independent relaxation of arteries [43,44]. Second, the increased DPP-4 activity was reported in T2DM when accompanied with a significant degree of insulin resistance (IR) [43], i.e., DPP-4 was recently proposed as a novel adipokine linking obesity to metabolic syndrome (MS) [45-47]. It should be kept in mind that IR is often associated with abnormal lipid metabolism and hypertension, and those two traditional $\mathrm{CV}$ risk factors may explain the increase in AS in T2DM and MS as well as the potential benefit of DPP-4 inhibition derived therapies.

\section{Conclusion}

DPP-4 inhibitors could have a beneficial effect not only on blood glucose levels but also on blood pressure and artery function. It should be noted however that there are several limitations in our study. The greatest drawback of the study is the lack of placebo-treated group which emphasises the possibility that the DPP-4i observed therapy benefit might be due to lifestyle changes during the treatment period. In addition, due to small number of participants and 12-week follow up accompanied by the fact the study was uncontrolled and open-label, our results should be interpreted with caution. Further large randomized placebo controlled long-term studies are required to evaluate the effect of gliptines on vascular function, inflammation and dyslipidemia in patients with T2DM.

\section{Authors' contributions}

LD made conception and design of the study, KB acquisited and interpreted the data; LD and KB drafted the manuscript and LD furthermore revised it critically for important intellectual content; both authors have given final approval of the version to be published; and agree to be accountable for all aspects of the work in ensuring that questions related to the accuracy or integrity of any part of the work are appropriately investigated and resolved. Both authors read and approved the final manuscript.

\section{Author details}

${ }^{1}$ Vuk Vrhovac Clinic for Diabetes, Endocrinology and Metabolic diseases, Merkur University hospital, Dugi dol 4a, Zagreb, Croatia. ${ }^{2}$ School of Medicine, University of Zagreb, Zagreb, Croatia.

\section{Acknowledgements}

We sincerely appreciate the administration office effort, laboratory technical staff well as the nurses from Vuk Vrhovac University Clinic for their enthusiastic effort and assistance during the study duration.

\section{Competing interests}

The authors declare that they have no competing interests.

Received: 15 December 2015 Accepted: 9 March 2016

Published online: 22 March 2016

\section{References}

1. Brand FN, Abbot RD, Kannel WB. Diabetes, intermittent claudication and risk of cardiovascular events. The Framingham study. Diabetes. 1989;38:504-9.

2. Capellini VK, Celoto AC, Baldo CF, Olivon VC, Viaro F, Rodrigues AJ, Evora PR. Diabetes and vascular disease: basis concepts of nitric oxide physiology, endothelial dysfunction, oxidative stress and therapeutic possibilities. Curr Vasc Pharmacol. 2010;8:526-44.

3. UK Prospective Diabetes Study (UKPDS) Group. Effect of intensive bloodglucose control with metformin on complications in overweight patients with type 2 diabetes (UKPDS 34). Lancet. 1998;352:854-65.

4. Holman R, Retnakaran R, Farmer A, Stevens R. PROactive study. Lancet. 2006;367:25-6.

5. Action to Control Cardiovascular Risk in Diabetes (ACCORD). http://clinicaltrials.gov/ct/show/NCT00000620.

6. Kieffer TJ, Habener JF. The glucagon-like peptides. Endocr Rev. 1999;20:876-913.

7. Kieffer TJ, Mclntosh CH, Pederson RA. Degradation of glucose-dependent insulinotropic polypeptide and truncated glucagon-like peptide 1 in vitro and in vivo by dipeptidyl peptidase Iv. Endocrinology. 1995;136:3585-96. 
8. Mu J, Woods J, Zhou YP. Chronic inhibition of dipeptidyl peptidase-4 with a sitagliptin analog preserves pancreatic b-cell mass and function in a rodent model of type 2 diabetes. Diabetes. 2006;55:1695-704.

9. Ahrén B. Emerging dipeptidyl peptidase-4 inhibitors for the treatment of diabetes. Expert Opin Emerg Drugs. 2008;13:593-607.

10. Wei Y, Mojsov S. Tissue-specific expression of the human receptor for glucagon-like peptide-1: brain, hearth and pancratic forms have the same deduced amino-acid sequence. FEBS Lett. 1995;358(3):219-24.

11. Green BD, Hand KV, Dougan JE, McDonnell BM, Cassidy RS, Grieve DJ. GLP-1 and related peptides cause a concentration-dependent ralaxation of rat aorta through a pathway involving KATP and CAMP. Arch Biochem Biophys. 2008;478(2):136-42.

12. Ban K, Noyan-Ashraf M, Hoefer J, Bolz SS, Drucker DJ, Husain M. Cardioprotective and vasodilatory actions of glucagon-like peptide 1 receptor are mediated through both glucagon-like peptide 1 receptor-dependent and -independent pathways. Circulation. 2008;117:2340-50.

13. Fadini GP, Avogaro A. Cardiovascular effects of DPP-4 inhibition: beyond GLP-1. Vascul Pharmacol. 2011;55:1-3.

14. Shah Z, Pineda C, Kampfrath T, Maiseyu A, Ying Z, Racoma I, Deiuliis J, Xu X, Sun Q, Moffatt-Bruce S, Villamena F, Rajagopalan S. Acute DPP-4 inhibition modulates vacular tone through GLP-1 independent pathways. Vascular Pharmacol. 2011;55(1-3):111-7.

15. Schmieder R, Raff U, Schmidt S, Kistner I, Friedrich S, Bramlage P, Ottv C. Effects of the DPP-inhibitor saxagliptin on early vascular changes in the retinal and systemic circulation. doi: 10.1093/eurheartj/eht307.P607. First published online: 1 Aug 2013.

16. Van Poppel PC, Netea MG, Smits P, Tack CJ. Vildagliptin improves endothelium-dependent vasodilatation in type 2 diabetes. Diabetes Care. 2011;34:2072-7.

17. Koren S, Shemesh-Bar L, Tirosh A, Peleg RK, Berman S, Hamad RA, Vinker S, Golik A, Efrati S. The effect of sitagliptin versus glibenclamide on arterial stiffness, blood pressure, lipids, and inflammation in type 2 diabetes mellitus patients. Diabetes Technol Ther. 2012;14(7):561-7.

18. Derosa G, Ragonesi PD, Carbone A, Fogari E, D'Angelo A, Cicero AF, Maffioli P. Vildagliptin action on some adipocytokine levels in type 2 diabetic patients: a 12-month, placebo-controlled study. Expert Opin Pharmacother. 2012;13:2581-91

19. Schram M, Henry R, van Dijk R, Kostense PJ, Dekker JM, Nijpels G, Heine RJ, Bouter LM, Westerhof N, Stehouwer CD. Increased central artery stiffness in impaired glucose metabolism and type 2 diabetes. The Hoorn Study. Hypertension. 2004;43:176-81.

20. Henry R, Kostense P, Spijkerman A, Dekker JM, Nijpels G, Heine RJ, Kamp O, Westerhof N, Bouter LM, Stehouwer CD. Arterial stiffness increases with deteriorating glucose tolerance status. The Hoorn Study. Circulation. 2003;107:2089-95.

21. Boutouyrie P, Tropeano Al, Asmar R, Gautier I, Benetos A, Lacolley P, Laurent $\mathrm{S}$. Aortic stiffness is an independent predictor of primary coronary events in hypertensive patients: a longitudinal study. Hypertension. 2002;39:10-5

22. Asmar R, Rudnichi A, Blacher J, London GM, Safar ME. Pulse pressure and aortic pulse wave are markers of cardiovascular risk in hypertensive populations. Am J Hypertens. 2001;14:91-7.

23. James PA, Oparil S, Carter BL, Cushman WC, Dennison-Himmelfarb C, Handler J, Lackland DT, LeFevre ML, MacKenzie TD, Ogedegbe O, Smith SC Jr, Svetkey LP, Taler SJ, Townsend RR, Wright JT Jr, Narva AS, Ortiz E. Evidence-based guideline for the management of high blood pressure in adults: report from the panel members appointed to the Eighth Joint National Committee (JNC 8). JAMA. 2014;311:507-20.

24. Friedewald WT, Levy RI, Fredrickson DS. Estimation of the concentration of low-density lipoprotein cholesterol in plasma, without use of the preparative ultracentrifuge. Clin Chem. 1972;18:499-502.

25. Herman GA, Bergman A, Stevens C, Kotey P, Yi B, Zhao P, Dietrich B, Golor G, Schrodter A, Keymeulen B, Lasseter KC, Kipnes MS, Snyder K, Hilliard D, Tanen M, Cilissen C, De Smet M, de Lepeleire I, Van Dyck K, Wang AQ, Zeng W, Davies MJ, Tanaka W, Holst JJ, Deacon CF, Gottesdiener KM, Wagner JA. Effect of Single Oral Doses of Sitagliptin, a Dipeptidyl Peptidase-4 Inhibitor, on Incretin and Plasma Glucose Levels afte ran Oral Glucose Tolerance Test in Patients with Type 2 Diabetes. J Clin Endocrinol Metab. 2006:91:4612-9.

26. Lloyd-Jones D, Adams RJ, Brown TM, Carnethon M, Dai S, De Simone G, Ferguson TB, Ford E, Furie K, Gillespie C, Go A, Greenlund K, Haase N,
Hailpern S, Ho PM, Howard V, Kissela B, Kittner S, Lackland D, Lisabeth L, Marelli A, McDermott MM, Meigs J, Mozaffarian D, Mussolino M, Nichol G, Roger VL, Rosamond W, Sacco R, Sorlie P, Stafford R, Thom T, WasserthielSmoller S, Wong ND, Wylie-Rosett J. American Heart Association Statistics Committee and Stroke Statistics Subcommittee. American Heart Association Statistics Committee and Stroke Statistics Subcommittee: executive summary: heart disease and stroke statistics - 2010 update: a report from the American Heart Association. Circulation. 2010;121:948-54.

27. Roman MJ, Deveraux RB, Schwartz JE, Lockshin MD, Paget SA, Davis A, Crow MK, Sammaritano L, Levine DM, Shankar BA, Moeller E, Salmon JE. Arterial stiffness in chronic inflammatory diseases. Hypertension. 2005;46:194-9.

28. Vlachopoulos C, Dima I, Aznaouridis K, Vasiliadou C, loakeimidis N, Aggeli C, Toutouza M, Stefanadis C. Acute systemic inflammation increases arterial stiffness and decreases wave reflections in healthy individuals. Circulation. 2005;112:2193-200.

29. Maki-Pataja KM, Booth AD, Hall FC, Wallace SM, Brown J, McEniery CM, Wilkinson IB. Ezetimibe and simvastatin reduce inflammation, disease activity, and aortic stiffness and improve endothelial function in rheumatoid arthritis. J Am Coll Cardiol. 2007;50:852-8.

30. Mackenzie IS, Wilkinson IB, Cockroft J. Assessment of arterial stiffness in clinical practice. QJM. 2002;95:67-74.

31. Tedesco MA, Natale F, Di Salvo G, Caputo S, Capasso M, Calabro R. Effects of coexisting hypertension and type II diabetes mellitus on arterial stiffness. J Hum Hypertens. 2004;18:469-73.

32. Lee JM, Shirodaria C, Jackson CE, Robson MD, Antoniades C, Francis JM, Wiesmann F, Channon KM, Neubauer S, Choudhury RP. Multimodal magnetic resonance imaging quantifies atherosclerosis and vascular dysfunction in patients with type 2 diabetes mellitus. Diab vasc Dis Res. 2007:4:44-8.

33. Van der Meer RW, Diamant M, Westenberg JJ, Doornbos J, Bax JJ, de Roos A, Lamb HJ. Magnetic resonance assessment of aortic pulse wave velocity, aortic distensibility, and cardiac function in uncomplicated type 2 diabetes mellitus. J Cardiovasc Magn Reson. 2007;9:645-51.

34. Ott C, Raff U, Schmidt S, Kistner I, Friedrich S, Bramlage P, Harazny JM, Schmieder RE. Effects of saxagliptin on early microvascular changes in patients with type 2 diabetes. Cardiovasc Diabetol. 2014;14(13):19. doi:10.1186/1475-2840-13-19.

35. Derosa G, Maffioli P, Ferrari I, Mereu R, Ragonesi PD, Querci F, Franzetti IG, Gadaleta G, Ciccarelli L, Piccinni MN, D'Angelo A, Salvadeo SA. Effects of one year treatment of vildagliptin added to pioglitazone or glimepiride in poorly controlled type 2 diabetic patients. Horm Metab Res. 2010;42:663-9.

36. Zografou I, Sampanis C, Gkaliagkousi E, Iliadis F, Papageorgiou A, Doukelis P, Vogiatzis K, Douma S. Effect of vildagliptin on hsCRP and arterial stiffness in patients with type 2 diabetes mellitus. Hormones. 2015;14(1):118-25.

37. Mistry GC, Maes AL, Lasseter KC, Davies MJ, Gottesdiener KM, Wagner JA, Herman GA. Effect of sitagliptin, a dipeptidyl peptidase-4 inhibitor, on blood pressure in non diabetic patients with mild to moderate hypertension. J Clin Pha rmacol. 2008;48:592-8.

38. Marney A, Kunchakarra S, Byrne L, Brown NJ. Interactive hemodynamic effects of dipeptidyl peptidase -IV inhibition and angiotensin-converting enzyme inhibition in humans. Hypertension. 2010;56:728-33.

39. Aroor AR, DeMarco VG, Jia G, MartinezLemus LA, Habibi J, Sun Z, Garro M, Meininger GA, Sowers JR. Dipeptidyl Peptidase-4 (dpp-4) Inhibition Decreases Cardiac And Vascular Stiffness And Improves Cardiac And Vascular Relaxation In Western Diet Fed Mice. Hypertension. 2014;64:A655.

40. Satoh-Asahara N, Sasaki Y, Wada H, Tochiya M, Iguchi A, Nakagawachi R, Odori S, Kono S, Hasegawa K, Shimatsu A. A dipeptidyl peptidase-4 inhibitor, sitagliptin, exerts anti-inflammatory effects in type 2 diabetic patients. Metabolism. 2013;62(3):347-51.

41. Vilsbøll T. Liraglutide: an once-daily GLP-1 analogue for the treatment of type 2 diabetes mellitus. Expert Opin Investig Drugs. 2007;16:231-7.

42. Monami M, Vitale V, Ambrosio VL, et al. Effects on lipid profile of dipeptidyl peptidase 4 inhibitors, pioglitazone, acarbose, and sulfonylureas: meta-analysis of placebo-controlled trials. Adv Ther. 2012;29(9):736-46.

43. Sun F, Wu S, Wang Y, Guo S, Chai S, Yang Z, Li L, Zhang Y, Ji L, Zhan S. Effect of Glucagon- like Peptide-1 Receptor Agonists on Lipid Proles Among Type 2 Diabetes: a Systematic Review and Network Meta-analysis. Clin Ther. 2015:37(1):225-41. 
44. Richter G, Feddersen O, Wagner U, Barth P, Goke R, Goke B. GLP-1 stimulates secretion of macromolecules from airways and relaxes pulmonary artery. Am J Physiol. 1993;265:L374-81.

45. Nystrom T, Gonon AT, Sjoholm A, Pernow J. Glucagonlike peptide-1 relaxes rat conduit arteries via an endothelium-independent mechanism. Regul Pept. 2005;125:173-7.

46. Firneisz G, Varga T, Lengyel G, Fehér J, Ghyczy D, Wichmann B, Selmeci L, Tulassay Z, Rácz K, Somogyi A. Serum dipeptidyl peptidase-4 activity in insulin resistant patients with non-alcoholic fatty liver disease: a novel liver disease biomarker. PLoS ONE. 2010;5(8):e12226. doi:10.1371/journal. pone.0012226.

47. Lamers D, Famulla S, Wronkowitz N, Hartwig S, Lehr S, Ouwens DM, Eckardt K, Kaufman JM, Ryden M, Müller S, Hanisch FG, Ruige J, Arner P, Sell $\mathrm{H}$, Eckel J. Dipeptidyl peptidase 4 is a novel adipokine potentially linking obesity to the metabolic syndrome. Diabetes. 2011;60(7):1917-25.
Submit your next manuscript to BioMed Central and we will help you at every step:

- We accept pre-submission inquiries

- Our selector tool helps you to find the most relevant journal

- We provide round the clock customer support

- Convenient online submission

- Thorough peer review

- Inclusion in PubMed and all major indexing services

- Maximum visibility for your research

Submit your manuscript at www.biomedcentral.com/submit
(O) Biomed Central 